\title{
The Use of Remote Sensing Techniques for the Detection of Salinization of the Euphrates River in the Provinces of Qadisiyah, Muthannain Iraq
}

\author{
Abdel-Muhsen A. Radhi Al-Jabery ${ }^{1}$, Aula Hussein Al-Obeidi ${ }^{2}$ \\ ${ }^{1}$ Assistant Professor, Department of Soil and Water in Agriculture College, University of Almuthanna, Iraq \\ ${ }^{2}$ Department of Soil and Water in Agriculture College, University of Almuthanna, Iraq
}

\begin{abstract}
Suffer the provinces of Qadisiyah, Muthanna marked increase salinity waters of the Euphrates compared to hndia dam, which reflected negatively on the quality of the Euphrates River within the study area This study aimed at finding the causes of salinization in the Euphrates River water in the provinces of Muthanna and Qadisiyah, And of total dissolved solids, locate fourteen station to measure river water pollution from the date of $01.11 .2014-31.10 .2015$ in addition to the identification of agricultural drainage and sewage sites nominated ground water and soil of the two provinces, And used Satellite imagery taken by sensor Ortho PMS with highest resolution $1.5 \mathrm{~m}$ and produced in the first package (pand 1) wavelength 0.455-0.525 Maekeromitr second package (pand 2) wavelength 0.530-0.590 Maekeromitr third package (pand 3) with a wavelength of 0.625-0.695 Maekeromitr and fourth package (pand 4) 0.760-0.890 Maekeromitr, It was the use of the program ENVI (v.51) to To conduct a classification supervised and unsupervised As it was calculated vegetation directory NDVI and guide Ground water cover LWM as use this index for the first time in this study on the global and local level as it is one of the indicators proposed and experimentally by NASA and the US in order to explore some of the characteristics of the studied water using a GIS 10.0 to compare the default attributes with the real qualities of the studied where he was sports therapy using Minitab software 16 to obtain the equations used were correlation work between the default values and truth using Curve Expert Professional program (V.2.3). As the results showed that the coefficient of determination and lower the standard average values for sports Nmozjat values indicate the possibility of exploring all of the qualities of the physical and chemical water quantitatively under the conditions of this study, using visuals and satellite programs, remote sensing.
\end{abstract}

Keywords: a remote sensing, salinization, salinization of the Euphrates River, the Euphrates River

\section{Introduction}

The study of the concentration of dissolved salts in the water an important issue to evaluate the validity of the water for irrigation and drinking directly affected and in soil salinization Where he created a problem of salinity, which are becoming increasingly with the increasing demand for water is salted with water, especially rivers and lakes of the most dangerous types of pollution they represent the main source of water used for drinking, agriculture, water and exist in Iraq, in its various forms, a surface water and rain, groundwater and differ from each other in terms of quantities, physical and chemical specifications and their economic importance and did not optimize the use of these sources is achieved because of the many problems retardation irrigation and drainage system and the large number of waste and the lost in the water Especially Euphrates River, which flows from the territory of neighboring countries with tributaries flowing into the water located headwaters outside Iraq, Making Iraq vulnerable to the threat of neighboring countries through the use of water as the power available has as well as the occurrence of Iraq as part of Arid and semi-arid with a severe shortage the falling Rainfall and with desertification factors that took gripping large areas of Iraq.The increase in the pollution problem in addition to the technical development in the areas of life imposed on specialists and researchers search for unconventional approaches to pollution control in all fields as remote sensing which is of the important techniques to detect and monitor the water pollution problem through the data and information provided by this technology.
Accounting for sensing the most effective tool is best suited for data that occupy large areas compared to conventional hydrological methods, Considering aerial photographs and one of the most important sources of remote sensing effective in conducting hydrological quantitative measurements (Jordan et al, 2005).

\section{Remote Sensing}

Definitions sensor technology has numerous remote given the multiplicity of uses and applications of this technology, Knew Baumgardner, 1980 that a series of interactions between matter and energy of the radiation and can receive information through ground-reflectivity material, As Lulu 1998 has sensors known after that technology is the study of things at a distance without contact physicist directly with the aim of collecting data, and then processing these data to obtain the required information this process and conduct of the various ground and air platforms and satellite heights ranging from several meters to thousands and knew Lilleas and Kiffer, 2000 sensing that the science and art to get information about the object or area or phenomenon mediated sensitivity of different platforms devices (ground, air and satellite) and analysis of the data obtained provided they do not get physical contact and using the electromagnetic spectrum. He explained that it can be used for wavelengths outside of the possibility of the human eye (0.4-0.7 $\mu \mathrm{m})$, so he knew that Science visualizations. Sensing activities include many remote and a lot of activities, the operation of satellite systems operations, data acquisition in the form of images, storage and processing of 


\section{International Journal of Science and Research (IJSR) \\ ISSN (Online): 2319-7064 \\ Index Copernicus Value (2013): 6.14 | Impact Factor (2015): 6.391}

this data later, then interpret and disseminate the outputs of images and data (Chuvieco and Huete, 2010). The first principle of remote sensing techniques is to rely on the power source to illuminate the target (unless the aim was self-emitting) and this energy is in the form of electromagnetic radiation caused interacts electric field with magnetic field diffuse in to the air and other media Which source foundation the sun (Dagestani, 2003). The degree of clarity of objectives and features of the ground (water, soil, vegetation) in the satellite images depends on the amount of reflected rays from those goals and connecting to sensors and detectors satellites (Adruy, 1990).

\section{Spectral Reflectivity of Water}

Can identify water bodies with remote sensing easily using wavelengths Infrared nearby region and the medium while Can be determined some cases of water Better use of visible wavelengths Radiology (Thomas, 1994), The water-highest reflectivity at shorter wavelengths than $0.6 \mathrm{~m}$ and And nonexistent reflectivity of water at length $0.7 \mathrm{~m}$ and more, Because water absorbs portion infrared reflection nearby and for this reason is often used fumbling this wavelength for the purpose of defining the borders of water bodies and mapped because of the emergence of these bodies Dark, which suitable with the ground adjacent to appear then the edges of these Waterbodies sharp detail, easily traced in the satellite image (Sawin \& Davis, 1978).

\section{Spectral Directories}

Vegetation guide (NDVI) is a digital indicator is simple, which helps in some analyzes used in the measurements of remote sensing NDVI is related to vegetation, where healthy vegetation reflects very well in the near infrared part of the spectrum. Index values can range from -1.0 to 1.0 , but vegetation values typically range between 0.1 and 0.7 Free standing water (ocean, sea, lake, river, etc.) gives a rather low reflectance in both spectral bands and thus result in very low positive or even slightly negative NDVI values. Soils which generally exhibit a near-infrared spectral reflectance somewhat larger than the red, and thus tend to also generate rather small positive NDVI values (say 0.1 to 0.2 ). (NASA, 2015).

NDVI $($ ETM +$)=(1.5 *($ Band $3-$ Band 2$) /($ Band $3+$ Band 2) +0.05$)$

Ground cover and water proof (LWM) IS Land and Water Mask index is a very useful tool to differentiate between land and water. This is very important variable to classify all type of water bodies. Index values can range from 0 to 255 , but water values typically range between 0 and 50 . (NASA, 2015).

Land \& Water Mask $($ LWM $)=($ band4 $) /($ band $2+0.0001)$ *100)

\section{Study Area}

Conducting research in central and southern Iraq, an area on the Euphrates river path, starting from the city of Abu Sakhir to Batha for the purpose of studying the causes of salinization of the Euphrates River in the provinces of Qadisiyah, Muthanna has included search and forest areas following the river :riverbed between the cities of Abu Sakhir and Batha., Agricultural drainage that are in the course of the river and its branches within the search area. The effect of water springs in the area of research on the Euphrates River, and The impact of sewage water for cities downstream networks.

Table 1: Shows the coordinates of the study stations

\begin{tabular}{|c|c|c|}
\hline \multirow{2}{*}{ Codestations } & \multicolumn{2}{|c|}{ coordinates } \\
\hline & Easting & northing \\
\hline S1 & 44.492023 & 31.914317 \\
\hline S2 & 44.477184 & 31.704118 \\
\hline S3 & 44.511164 & 31.782772 \\
\hline S4 & 44.647713 & 31.578013 \\
\hline S5 & 44.614677 & 31.750855 \\
\hline S6 & 44.601018 & 31.555004 \\
\hline S7 & 45.150673 & 31.418215 \\
\hline S8 & 45.229088 & 31.358216 \\
\hline S9 & 45.123977 & 31.294768 \\
\hline $\mathrm{S} 10$ & 45.055660 & 31.335003 \\
\hline S11 & 45.301544 & 31.315686 \\
\hline $\mathrm{S} 12$ & 45.543522 & 31.199328 \\
\hline S13 & 45.723006 & 31.172224 \\
\hline S14 & 45.880024 & 31.124050 \\
\hline
\end{tabular}

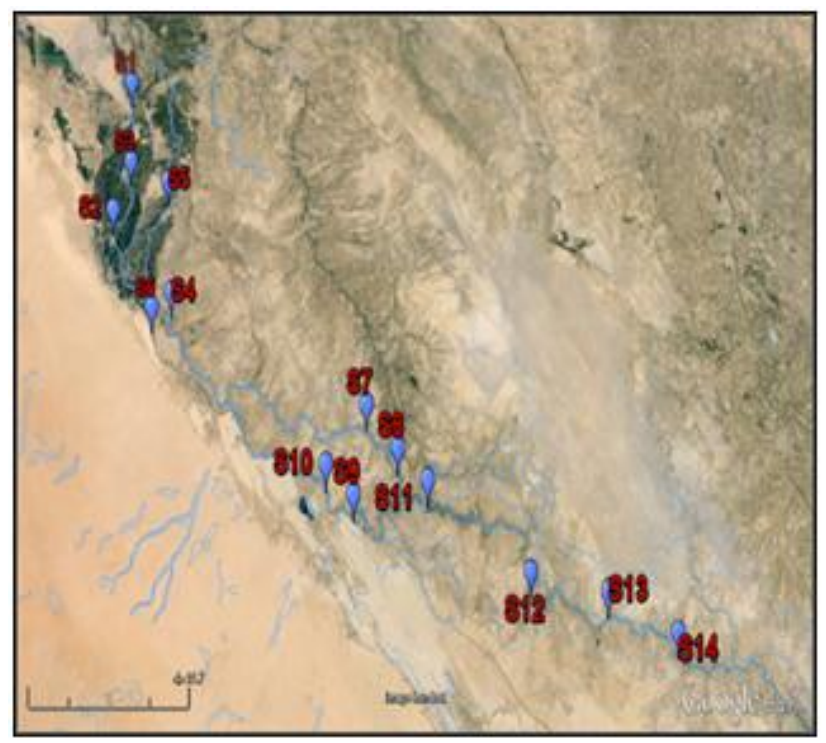

Figure 1: satellite image of the study area is taken from the website (Google) shows water sampling sites.

\section{Results and Discussion}

\section{Spectral evidence:}

The table shows (2) spectral evidence used values of vegetation guide NDVI values (Normalized Difference Regelation) and a guide cover LWM (Land Water Mask) were obtained on these values for signs spectral for using the GIS 10 program and extracted from the images satellite spot 6 and apply equations directories

Land \& Water Mask $($ LWM $)=($ band4 $) /($ band $2+0.0001)$ $* 100$ )

Where the wavelengths Albandhat satellite image Band1:blue: 0.455-0.525 $\mu \mathrm{m}$ 


\section{International Journal of Science and Research (IJSR) ISSN (Online): 2319-7064}

Index Copernicus Value (2013): 6.14 | Impact Factor (2015): 6.391

Band2:red: 0.530-0.590 $\mu \mathrm{m}$

Band3:green: 0.625-0.695 $\mu \mathrm{m}$

Band4:near infrared: 0.760-0.890 $\mu \mathrm{m}$.

Table 2: The spectral directories that are used

\begin{tabular}{|c|c|}
\hline NDVI & LWM \\
\hline 0.099827664 & 132.9887424 \\
\hline 0.097866545 & 167.6545456 \\
\hline 0.099647644 & 150.6554728 \\
\hline 0.089285716 & 31.48142433 \\
\hline 0.099564566 & 100.7532529 \\
\hline 0.092647061 & 161.363266 \\
\hline-0.618964326 & 30.67765431 \\
\hline-0.606818199 & 49.99750137 \\
\hline-0.139285728 & 83.3326416 \\
\hline 0.090564566 & 88.87675645 \\
\hline-0.617988543 & 29.69995117 \\
\hline-0.120652176 & 33.33296204 \\
\hline-0.120653528 & 30.46725286 \\
\hline-0.128754331 & 72.33876789 \\
\hline
\end{tabular}

It is clear that the evidence NDVI values ranged from $(0.618964326-)$ to $(0.099827664)$ ranged from LWM (29.69995117) to values (167.6545456).

The Table (3) shows the results of the linear regression analysis for using the program minitab 16.0 for the purpose of Mathematical processing, and it is clear that the concentrations of some of the qualities and chemical elements of water has been associated with different connections, including the concentration of the EC, Associated relationship linear regression High significance with the proportions of the ndvi and lwm as was a highly significant correlation $(r=0.887)$ and the value of the coefficient of determination (0.786) and the value of low standard error and by (0.592) either the TDS also been the tds also been associated with a highly significant correlation with the guides values $(r=0.856)$ and the value of the coefficient of determination (0.733) and the value of the standard error is low (439.857) as well as the turbidity associated with the two guides highly significant values of correlation $(\mathrm{r}=0.887)$ and the standard error was also low value (7.483), The SAR Aterbtt highly significant correlation with the two guides $(\mathrm{r}=0.924)$ and total hardness also been associated with a highly significant correlation $(r=0.870)$ and mistake a record low for the two traits, either all the elements associated with the relationship linear regression high with two guides where the sodium highly significant correlation $(\mathrm{r}=0.909)$ and by a factor of identification (.826) and the value of a record low line (73.848) and was associated with calcium and magnesium highly significant relationship $(\mathrm{r}=0.814)(\mathrm{r}=0.929)$, respectively, and also the value of Lowest standard error, either chloride element Was associated relationship slope of a linear high significance with the two guides $(r=0.889)$ and by a factor of determining (0.790) and the value of the standard error (179.706), The sulfates also was a highly significant correlation $(\mathrm{r}=0.837)$ and the coefficient determining (.701) record and a line a few (198.66), we note through these links that can be concluded this quality characteristics of the water using these directories and adoption of the resulting values and comparing different concentrations.
Table 3: Spectroscopic evidence for each element

\begin{tabular}{|c|c|c|c|c|}
\hline Adjective & Mathematical Model & $\mathrm{R}$ & $\mathrm{R} 2$ & S.E \\
\hline $\mathrm{EC}$ & $\begin{array}{c}\mathrm{EC}=4.45-0.426 \text { NDVI - } \\
0.0184 \text { LWM }\end{array}$ & 0.887 & 0.786 & 0.592 \\
\hline TDS & $\begin{array}{c}\text { TDS }=2583-1079 \text { NDVI - } \\
8.24 \text { LWM }\end{array}$ & 0.856 & 0.733 & 439.857 \\
\hline TURB & $\begin{array}{c}\text { TURB }=32.5-35.7 \text { NDVI } \\
0.0818 \mathrm{LWM}\end{array}$ & 0.889 & 0.790 & 7.483 \\
\hline SAR & $\begin{array}{c}\mathrm{SAR}=6.85-1.61 \mathrm{NDVI}- \\
0.0264 \mathrm{LWM}\end{array}$ & 0.924 & 0.854 & 0.768 \\
\hline $\mathrm{TH}$ & $\begin{array}{c}\mathrm{TH}=1066-8 \mathrm{NDVI}-3.17 \\
\text { LWM }\end{array}$ & 0.870 & 0.757 & 102.952 \\
\hline $\mathrm{Na}$ & $\begin{array}{c}\text { NA }+=580-106 \text { NDVI - } \\
2.43 \text { LWM }\end{array}$ & 0.909 & 0.826 & 73.848 \\
\hline $\mathrm{Ca}$ & $\begin{array}{c}\mathrm{Ca}+2=174+1.1 \text { NDVI - } \\
0.395 \text { LWM }\end{array}$ & 0.814 & 0.663 & 15.804 \\
\hline $\mathrm{Mg}$ & $\begin{array}{c}\mathrm{Mg}+2=135+0.17 \mathrm{NDVI}- \\
0.338 \text { LWM }\end{array}$ & 0.929 & 0.863 & 7.620 \\
\hline $\mathrm{Cl}$ & $\begin{array}{c}\mathrm{Cl}-1=1155-115 \mathrm{NDVI}- \\
5.72 \mathrm{LWM}\end{array}$ & 0.889 & 0.790 & $17 \mathrm{c}$ \\
\hline Hco3 & $\begin{array}{c}\text { HCO3 }=239-15.8 \text { NDVI - } \\
0.468 \text { LWM }\end{array}$ & 0.869 & 0.756 & 17.001 \\
\hline So4 & $\begin{array}{c}\text { So4- }=1139-62 \text { NDVI - } \\
5.14 \text { LWM }\end{array}$ & 0.837 & 0.701 & 198.666 \\
\hline
\end{tabular}
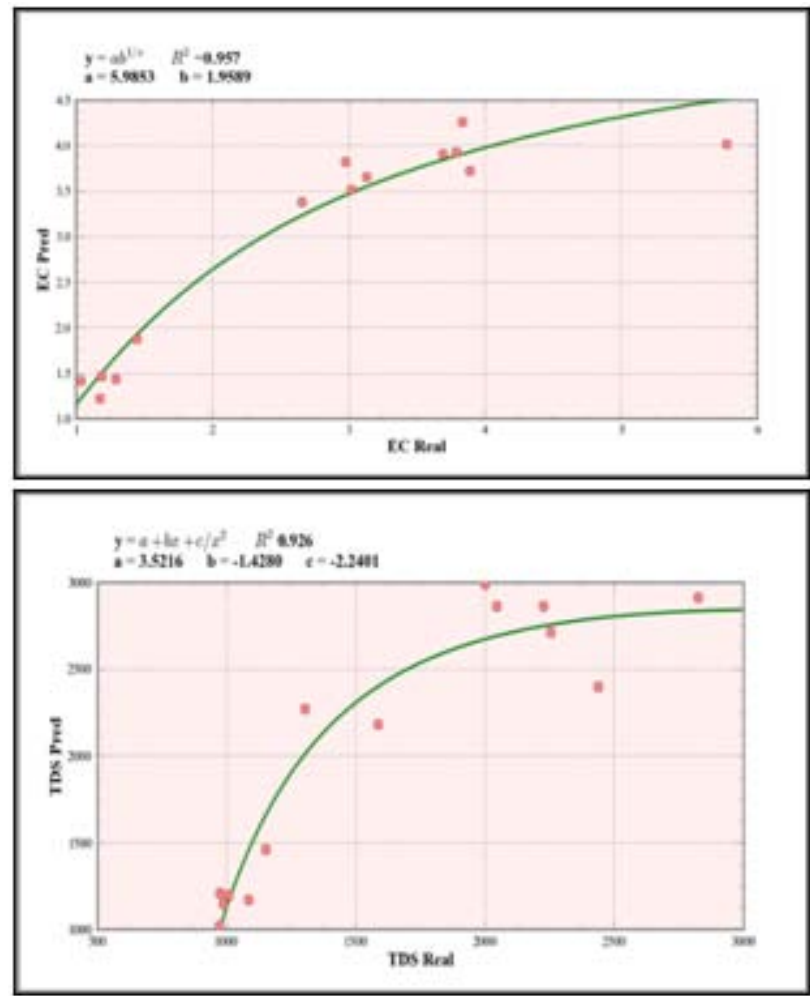

Form (2) shows the correlation between the values derived from satellite imagery and true values of some elements and characteristics of the water using carve program expert professional sports for the purpose of data processing. The highest correlation between the real electrical conductivity values and the values default satellite images during the year was in the second quarter (January) as seen from the figure that the relationship between them is negative slope of a linear relationship with a high correlation ratio $(r=0.978)$ and was the best equation to describe this relationship is the equation type of root as evidenced by the total solids may have been associated with the values of the picture elements a linear relationship with a slope of negative correlation $(r=$ 0.962 ) and the best equation to describe this relationship is

\section{Volume 5 Issue 8, August 2016}




\section{International Journal of Science and Research (IJSR) \\ ISSN (Online): 2319-7064 \\ Index Copernicus Value (2013): 6.14 | Impact Factor (2015): 6.391}

highly significant correlation the equation (Heat capacity). The SAR values may have been associated with the satellite images the values of relationship linear slope is negative with a highly significant correlation $(r=0.969)$ for the month of November and the best equation to describe this relationship (saturation growth rate), and was higher correlation between total hardness and default values satellite images during the year was in the month of January, their relationship is negative slope of a linear relationship with the highly significant correlation $(r=0.896)$ and was the best equation to describe this relationship (power). The highest correlation during the year between turb truth and default values during the month of January as the relationship between the negative slope of a linear relationship with a high correlation moral $(\mathrm{r}=0.908)$ and the best equation to describe this relationship (root) as the water containing the stuck materials increases reflection the degree commensurate with the concentration and quality of the outstanding material in it Where the energy reflected from the surface of the water increases with turbidity this is consistent with what was said (2000, lilles and and kiefer; Jensen, 2007), The correlation of the elements with default values was the element calcium highly significant correlation and factor identification $(\mathrm{r} 2=0.80)$ was the best equation to describe this relationship is a kind of (root) of sodium and element was highly significant correlation is also a factor determining ( $\mathrm{r} 2=0.837)$ and was the best an equation to describe this relationship is of the type (power), either chloride showed an high correlation moral factor identification ( $\mathrm{r} 2=0.896)$ and was the best equation to describe this relationship is a kind of (root), be The equation (power) best equation to describe the correlation of bicarbonate and a factor define $(\mathrm{r} 2=0.766)$ were the equation (Hoerl) equation best described the moral high correlation between the truth and the default values for each of magnesium and determining factor (0.877) and sulphate factor identification (0.827).
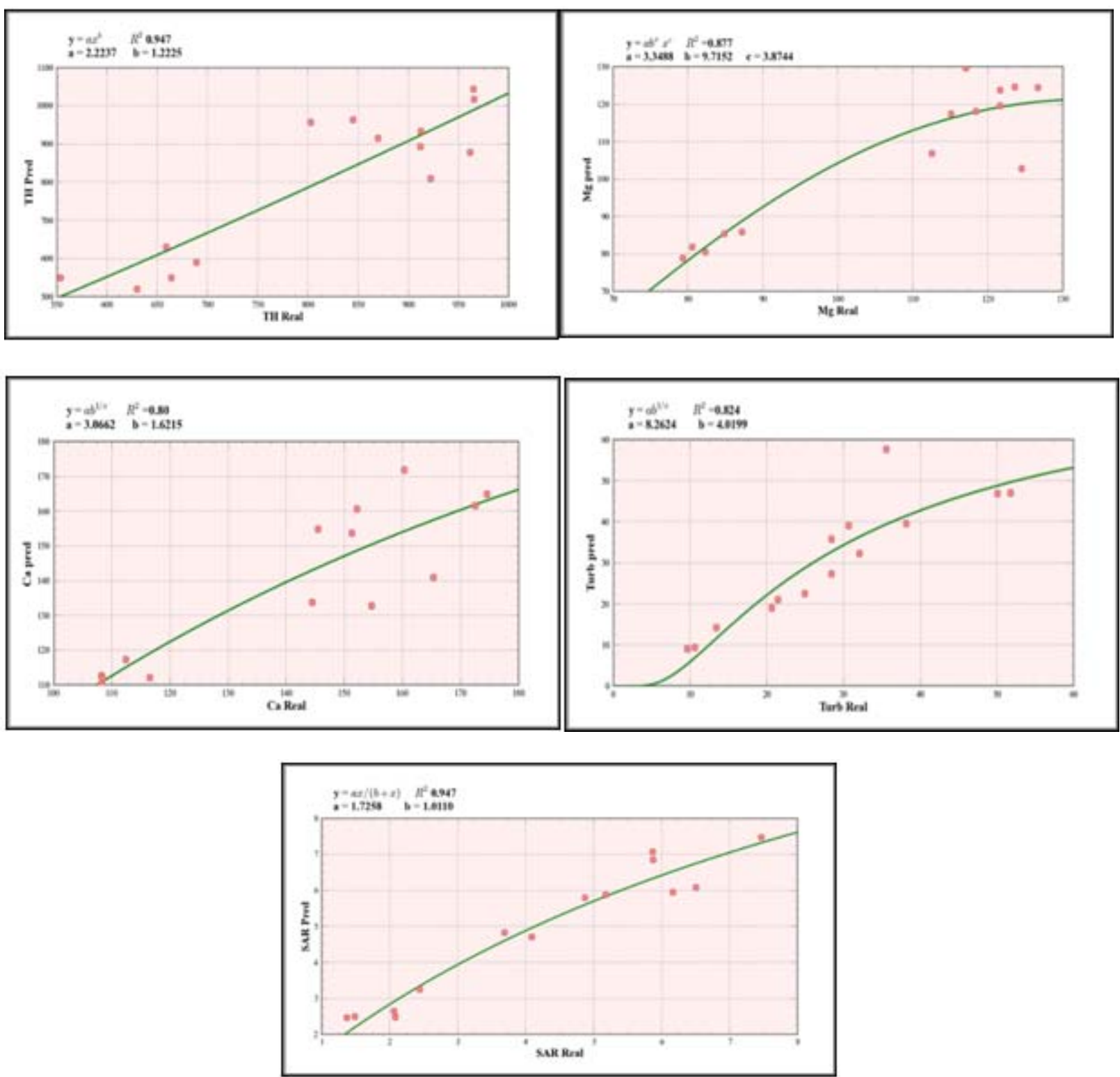

Volume 5 Issue 8, August 2016 www.ijsr.net 


\section{International Journal of Science and Research (IJSR) \\ ISSN (Online): 2319-7064}

Index Copernicus Value (2013): 6.14 | Impact Factor (2015): 6.391

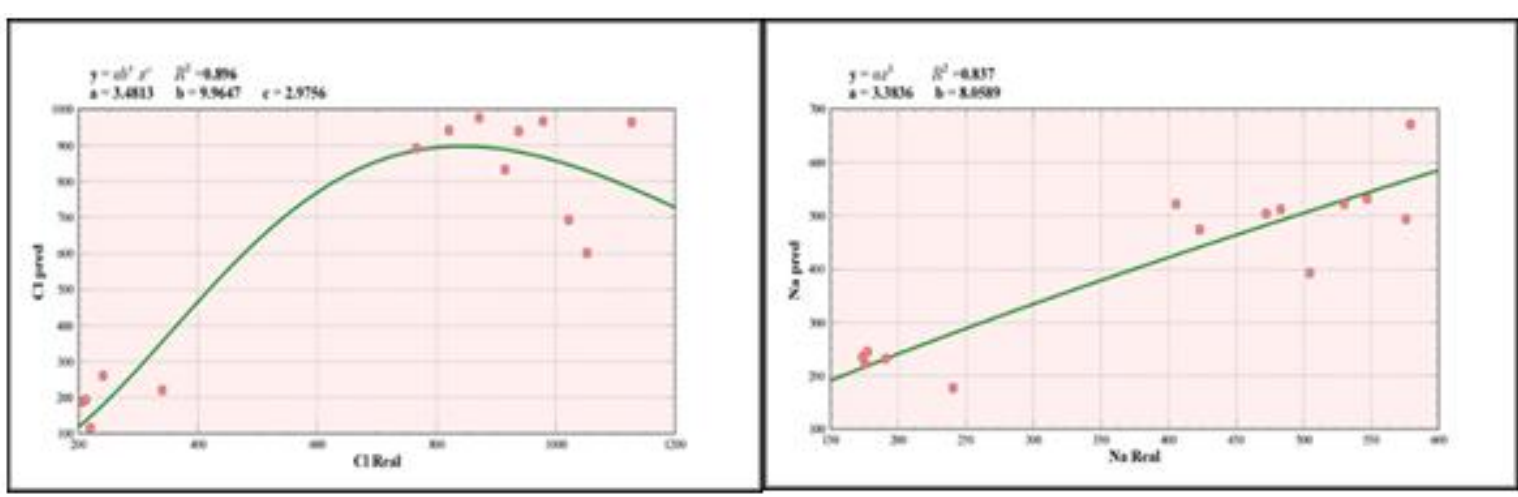

Form 2: shows the correlation between the values derived from satellite imagery and true values of some elements and characteristics of the water

\section{Conclusions}

- The possibility of exploring all of the qualities of water under the conditions of this study, and for using the visuals and satellite remote sensing programs.

- The presence of highly significant correlation showing the effect of chemical ions to increase the concentration of total dissolved salts in the river.

- The presence of the decline related to a factor of highselect a standard and low line between the true values that have been measured in vitro and default values used satellite images.

\section{References}

[1] Jordan, E.; L. Ungerec hts, ; B. Caceres, ; A. penaeiel, and $B$. francon (2005). Estimation by photogrammetry of the glacier recession on the eotopati volcano (Ecnador) between 1950and1997, Henydrological science Journal, Vol. 50, No.6, PP.949961.

[2] Baumgardner, M.F. and the LARS Staff, (1980). Extension of laboratory measured soil spectra to field condition. soil Sci.Soc. Am.J.44.

[3] Lulu, Abdul Rahim, (1998). devoted to earth observation satellite systems. General Authority for Remote Sensing. Presidency of the Council of Ministers, the Syrian Arab Republic.

[4] Lillesand T. M. \& Kiefer R. W., (2000). Remote Sensing and Image Interpretation, 4th ed. Wiley \& Sons.

[5] Chuvieco, E. and Huete, A. (2010). Fundamental of satellite remote sensing, Taylor and Francis Group, New York.

[6] Dagestani, Nabil Sobhi, (2003). "Remote sensing fundamentals and applications" Balqa Applied University, Dar curriculum, Amman.

[7] Adruy, S., (1990)" A guide To Remote Sensing Interpreting Images of The Earth ",, P120.

[8] Thomas, for Alsand and Ralph, Kiefer, translation sheep, Hassan Helmy (1994) "Remote sensing and interpretation of visuals," The Arab Center for Arabization, Translation, Authorship and publishing, Damascus.

[9] Swain, P.H., and Davis, S.M, (1978), Remote Sensing: The Quantitative Approach (NewYork:McGraw-Hil).
[10] NASA. )2015(land cover mapping using Landsat data training manual. www.servirglobal.net.

\section{Author Profile}

Dr. Abdel-Muhsen A. Radhi Al-Jabery graduated from university of Basra and got his phD in Soil Physics in university of Al-Muthanna, Iraq.

Aula Hussein Al-Obeidi graduated from University of AlMuthanna. Iraq, in addition, currently undergraduate student in same University at agriculture 